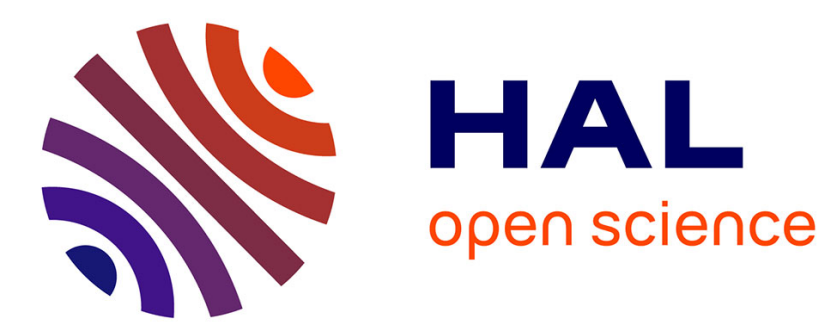

\title{
Deprotonative Cadmation of Functionalized Aromatics
}

J.M. L'Helgoual'Ch, Ghenia Bentabed-Ababsa, Floris Chevallier, M.

Yonehara, Masanobu Uchiyama, Aïcha Derdour, Florence Mongin

\section{To cite this version:}

J.M. L'Helgoual'Ch, Ghenia Bentabed-Ababsa, Floris Chevallier, M. Yonehara, Masanobu Uchiyama, et al.. Deprotonative Cadmation of Functionalized Aromatics. Chemical Communications, 2008, 42, pp.5375-5377. 10.1039/b809543d . hal-00783743

\section{HAL Id: hal-00783743 \\ https://hal.science/hal-00783743}

Submitted on 4 Feb 2014

HAL is a multi-disciplinary open access archive for the deposit and dissemination of scientific research documents, whether they are published or not. The documents may come from teaching and research institutions in France or abroad, or from public or private research centers.
L'archive ouverte pluridisciplinaire HAL, est destinée au dépôt et à la diffusion de documents scientifiques de niveau recherche, publiés ou non, émanant des établissements d'enseignement et de recherche français ou étrangers, des laboratoires publics ou privés. 


\title{
Deprotonative Cadmation of Functionalized Aromatics.
}

\author{
Jean-Martial L'Helgoual'ch, ${ }^{a}$ Ghenia Bentabed-Ababsa ${ }^{a, b}$ Floris Chevallier, ${ }^{a}$ Mitsuhiro Yonehara, ${ }^{c}$ \\ Masanobu Uchiyama, ${ }^{c}$ Aïcha Derdour ${ }^{b}$ and Florence Mongin ${ }^{a}$
}

\author{
Received (in XXX, XXX) 1st January 2007, Accepted 1st January 2007 \\ First published on the web 1st January 2007 \\ DOI: $10.1039 / b 000000 x$
}

\begin{abstract}
This communication describes the deproto-metalation of a large range of aromatics including heterocycles using a newly developed lithium-cadmium base. The reaction proceeds at room temperature with an excellent chemoselectivity and efficiency, 10 and proved to be regioselective in most cases.
\end{abstract}

The deprotonative metalation of aromatic rings has been widely used as a powerful method for regioselective functionalization. ${ }^{1}$ Various strong bases such as alkyllithiums and lithium dialkylamides have been largely employed for this 15 purpose because of their solubility in ethers and alkanes, and also because many of them are commercially available. However, the use of alkyllithiums on their own as bases has been limited to substrates with $\mathrm{C}-\mathrm{H}$ acidity enhanced by directing groups. In addition, recourse to simple lithium 20 dialkylamides for aromatics bearing reactive functions (e.g. ester or cyano groups) or sensitive $\pi$-deficient heterocycles required strictly controlled conditions (extremely low reaction temperatures, in situ trapping...) due to the high reactivity of the corresponding aryllithiums. The use of additives for

${ }_{25}$ lithium compounds in order to get more efficient or more chemoselective bases, or else to modify the deprotonation site, is a challenging area. Representative activation ways are the formation of chelates between alkyllithiums and $N, N, N^{\prime}, N^{\prime}-$ tetramethylethylenediamine (TMEDA), as well as the 30 formation of complexes between alkyllithiums and potassium tert-butoxide (e.g. LIC-KOR superbase).

By combining soft organometallic compounds with alkali additives (e.g. LiTMP, TMP = 2,2,6,6-tetramethylpiperidino, or $\mathrm{LiCl}$ ), bases such as ${ }^{t} \mathrm{Bu}_{2} \mathrm{Zn}(\mathrm{TMP}) \mathrm{Li},{ }^{2}{ }^{i} \mathrm{Bu}_{3} \mathrm{Al}(\mathrm{TMP}) \mathrm{Li},{ }^{3}$ ${ }_{35}\left(\mathrm{Me}_{3} \mathrm{SiCH}_{2}\right)_{2} \mathrm{Mn}(\mathrm{TMP}) \mathrm{Li} \cdot \mathrm{TMEDA},{ }^{4} \quad \mathrm{MeCu}(\mathrm{TMP})(\mathrm{CN}) \mathrm{Li}_{2}{ }^{5}$ and (TMP) ${ }_{2} \mathrm{Zn} \cdot 2 \mathrm{MgCl}_{2} \cdot 2 \mathrm{LiCl}^{6}$ have been prepared and used to generate functionalized aromatic compounds.

Mulvey introduced the term alkali metal-mediated metalation to depict the reactions of ate bases because the 40 reactivity ("synergy") they exhibit cannot be attained by the homometallic compounds on their own. ${ }^{7}$ When performed in tetrahydrofuran (THF), the reactions proved to be chemoselective, but require 1 or 2 equiv of base.

Herein we report an efficient regio- and chemoselective 45 direct cadmation on functionalized aromatics including very sensitive heterocycles using a newly designed lithium cadmate base. Among organometallics, organocadmium reagents have been mainly prepared by reaction of organic halides with cadmium metal or by transmetalation, and used as soft 50 nucleophilic reagents in organic synthesis. ${ }^{8}$ Wittig and coworkers documented in 1951 the synthesis of $\mathrm{Ph}_{3} \mathrm{ZnLi}$ and
$\mathrm{Ph}_{3} \mathrm{CdLi}$, and their efficiency to deprotonate fluorene in diethyl ether. ${ }^{9}$ Quenching with $\mathrm{CO}_{2}$ and subsequent acidic work-up afforded diphenyleneacetic acid in a low yield of $5516 \%$ after 10 days reaction time using $\mathrm{Ph}_{3} \mathrm{ZnLi}$ whereas a satisfying 64\% yield was obtained after 3 days using $\mathrm{Ph}_{3} \mathrm{CdLi}$, a result attributed to the size of the central metal. This prompted us to study the use of lithium cadmates for the deproto-metalation of sensitive aromatic substrates.

${ }_{60}$ A recent study showed LiTMP and (TMP) ${ }_{2} \mathrm{Zn}$, even if not associated in the form of a zincate, could behave synergically, combining both the efficiency of LiTMP and the chemoselectivity of $(\mathrm{TMP})_{2} \mathrm{Zn} .{ }^{10}$ In order to seek more efficient and direct methods for introducing functionalities 65 into heteroaromatic rings, we focused the deprotonative metalation using the corresponding mixture with cadmium instead of zinc on the difference of metal size. First attempts using anisole (1a) as substrate indicated that an in situ prepared mixture of $\mathrm{CdCl}_{2} \cdot \mathrm{TMEDA}^{11}$ (0.5 equiv) and LiTMP 70 (1.5 equiv) was suitable for an efficient reaction, when used in THF at room temperature. Indeed, subsequent trapping with iodine after 2 hours afforded the expected derivated 2a in 74\% yield, against $30 \%$ yield using $\mathrm{ZnCl}_{2} \cdot \mathrm{TMEDA}$ ( 0.5 equiv) and LiTMP (1.5 equiv). Since (TMP) ${ }_{2} \mathrm{Cd}$ (1 equiv) and LiTMP (1 75 equiv) give much lower conversions when used separately under the same reaction conditions, both of them play a role in the reaction mechanism. In order to obtain additional information about the active species of a basic mixture obtained from a THF solution of LiTMP and $\mathrm{CdCl}_{2} \cdot$ TMEDA ${ }_{80}$ (1/3 equiv), NMR and DFT studies were carried out. The analysis of the ${ }^{13} \mathrm{C}$ NMR spectra revealed that LiTMP was not present in solution, suggesting the formation of a lithium cadmate. This was confirmed by the B3LYP-calculated equilibrium between LiTMP and (TMP) ${ }_{2} \mathrm{Cd}$ on one side and ${ }_{85}$ (TMP) $)_{3} \mathrm{CdLi}$ on the other side, which is in sharp contrast to the corresponding zinc-lithium mixture obtained from LiTMP

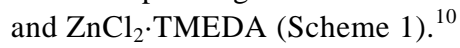

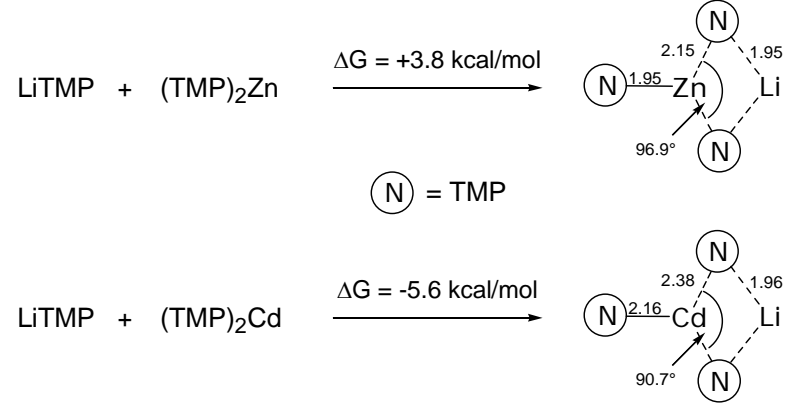

Scheme 1 Bond lengths at the B3LYP/6-31G*\&SVP(Zn) level in $\AA$ 
Representative results from the metalation-trapping sequences of benzenes bearing various directing metalation groups (DMG) using lithium tris(2,2,6,6tetramethylpiperidino)cadmate (TMP-cadmate) are 5 summarized in Table 1 . Veratrole (1b) was similarly regioselectively deprotonated. Polar functional groups including amide, ester, nitrile and even ketone (substrates 1c, 1d, 1e and 1f, respectively) are tolerated in the reaction. Aromatic halides $\mathbf{1 g}$ and $\mathbf{1 h}$ are chemoselectively converted to 10 the metalated derivatives, with a complete regioselectivity for the position far from the heavy halogen atom. Bromo ester $\mathbf{1 i}$ behaved similarly to give after trapping the iodide $\mathbf{2 i}$.

Table 1 Deprotonative cadmation of functionalized benzenes
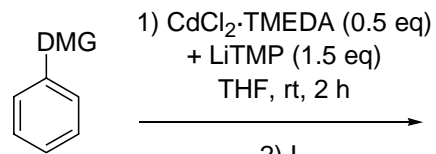

2) $\mathrm{I}_{2}$

\begin{tabular}{l} 
Entry Subs \\
\hline
\end{tabular}<smiles>COc1ccccc1OC</smiles><smiles>CCOC(=O)CC</smiles>

3<smiles>O=C(F)c1ccccc1</smiles>

4<smiles>COC(C)C</smiles>

5<smiles>[CH]</smiles><smiles>N#Cc1ccccc1</smiles>

6<smiles>O=C(c1ccccc1)c1ccccc1</smiles>

7<smiles>COc1ccc(Br)cc1</smiles>

8<smiles>COc1ccc(I)cc1</smiles>

9<smiles>CC(=O)c1ccc(Br)cc1</smiles>

$1 a$<smiles>COc1ccccc1I</smiles>

$1 b$<smiles>COc1cccc(C)c1OC</smiles>

2b $79 \%$

1c<smiles>CCOC(=O)OCC</smiles><smiles>NC(=O)c1ccccc1I</smiles>

2c $91 \%$

2d $62 \%$

1d<smiles>CC(=O)c1ccccc1I</smiles><smiles>N#Cc1ccccc1I</smiles>

1e

2e $68 \%$

If<smiles>O=Cc1ccccc1I</smiles>

2f $66 \%$

$1 g$<smiles>CC=COc1cc(Br)ccc1OC</smiles><smiles>COc1ccc(I)cc1C(=O)c1ccc(I)cc1</smiles>

2g $97 \%$

2h $83 \%$

2i $60 \%$
${ }^{a}$ Using $\mathrm{ZnCl}_{2} \cdot \mathrm{TMEDA}$ (0.5 eq) and LiTMP (1.5 eq).

15 We next demonstrated that TMP-cadmate was suitable for the chemoselective metalation of a large range of aromatic heterocycles, giving in general higher yields than using $\mathrm{Zn}^{10,12}$ (Table 2). The reaction with both $\pi$-excessive (substrates $\mathbf{1} \mathbf{j}$, $\mathbf{1 k}$ and $\mathbf{1 l}$ ) and $\pi$-deficient (substrates $\mathbf{1 m}, \mathbf{1 n}, \mathbf{1 0}, \mathbf{1 p}$ and $\mathbf{1 q}$ ) 20 heterocycles was found to proceed smoothly at RT. The expected iodides formed regioselectively, except 3iodopyridazine (2o), which was accompanied by the 4-iodo derivative 2'o (about 60/40 ratio for $2 \mathbf{2} / \mathbf{2}$ 'o).
Table 2 Deprotonative cadmation of aromatic heterocycles ${ }^{a}$

(2) (1) (2)

$25{ }^{a}$ Reactions carried out using $\mathrm{CdCl}_{2} \cdot$ TMEDA (0.5 eq) and LiTMP (1.5 eq). ${ }^{b}$ Using $\mathrm{ZnCl}_{2} \cdot$ TMEDA (0.5 eq) and LiTMP (1.5 eq). ${ }^{10,12{ }^{c}}$ Using $\mathrm{CdCl}_{2} \cdot$ TMEDA (1 eq) and LiTMP (3 eq). ${ }^{d}$ Using $\mathrm{CdCl}_{2} \cdot \operatorname{TMEDA}(0.33$ eq) and LiTMP (1 eq).

Starting from pyrazine (1q), the 2,5-diodo derivative $\mathbf{3 q}$ 30 was isolated concomitantly in $20 \%$ yield using 0.5 equiv of TMP-cadmate, probably through dideprotonation, whereas it was avoided using $1 / 3$ equiv. The formation of dimetalated derivatives being described using zincate $^{13}$ or manganate ${ }^{4,14}$ type bases, the use of a larger amount of TMP-cadmate (1 35 equiv) was attempted to deprotonate 1q. Under the same reaction conditions, the diiodide $\mathbf{3 q}$ was isolated in $58 \%$ yield. The method was successfully extended to five-membered substrates 1r, 1s, 1t and $\mathbf{1 l}$ (Table 3).

Table 3 Deprotonative dicadmation of aromatic heterocycles ${ }^{a}$

Entry Substrate (1)

${ }_{40}{ }^{a}$ Reactions carried out using $\mathrm{CdCl}_{2} \cdot$ TMEDA (1 eq) and LiTMP (3 eq). 
In summary, highly chemo- and regioselective deprotonative cadmation of functionalized aromatics including heterocycles was realized using a newly developed TMP-Cd-ate base. The latter is compatible with very sensitive 5 substrates such as diazines for which classical lithium bases can hardly be used, even at very low temperatures. ${ }^{15}$ The aromatic lithium cadmates were evidenced using iodine as electrophile. Trapping of the furylcadmate was attempted using other electrophiles: benzoyl chloride ${ }^{8 b}$ to afford the 10 ketone $\mathbf{4 u}$, and 4-bromoanisole to give the expected coupling ${ }^{16}$ product $\mathbf{5 u}$ under palladium catalysis, as depicted in Scheme 2.

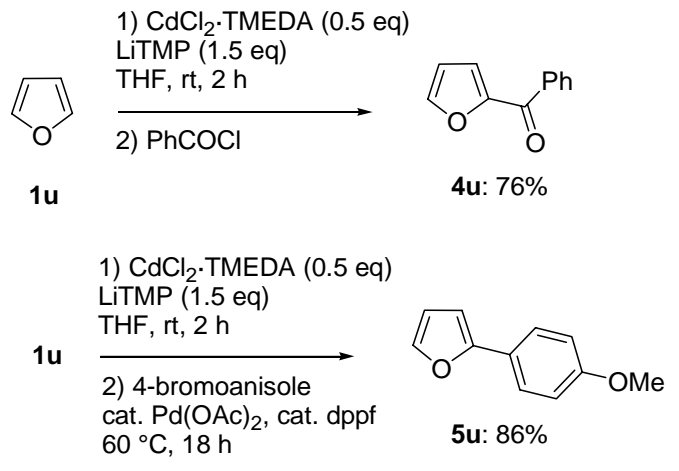

Scheme 2 Other trapping reactions of heterocyclic cadmates

15 Comparisons with previously described combinations of LiTMP on the one hand, and $\mathrm{Zn}^{2} \mathrm{Al}^{3} \mathrm{Mn}^{4}$ and $\mathrm{Cu}^{5}$ organometallic compounds on the other hand, showed the basic mixture we here described is both more efficient and/or more chemoselective.

20 Due to the toxicity of cadmium compounds, we actually try hard to develop basic mixtures containing cadmium salts as catalysts. In addition, works in order to develop new mixed lithium-metal bases of ate type still efficient and chemoselective but less toxic are in parallel under 25 investigation, profitting from the present study.

The authors gratefully acknowledge the financial support of Région Bretagne (to J.M.L.), MESRS of Algeria (to G.B.), and Hoansha and KAKENHI (Young Scientist (A), Houga, and Priority Area No. 452 and 459) (to M.U.). The 30 calculations were performed on the RIKEN Super Combined Cluster (RSCC).

\section{Notes and references}

${ }^{a}$ Chimie et Photonique Moléculaires, UMR 6510 CNRS, Université de Rennes 1, Bâtiment 10A, Case 1003, Campus Scientifique de Beaulieu, 3535042 Rennes, France. Fax: +33-2-2323-6955; E-mail:

florence.mongin@univ-rennes1.fr

${ }^{b}$ Laboratoire de Synthèse Organique Appliquée, Faculté des Sciences de l'Université, BP 1524 Es-Senia, Oran 31000, Algeria

${ }^{c}$ The Institute of Physical and Chemical Research, RIKEN, 2-1 Hirosawa, 40 Wako-shi, Saitama 351-0198, Japan. Fax: +81-48-467-2879; E-mail: uchi_yama@riken.jp

† Electronic Supplementary Information (ESI) available: Experimental procedures and characterizations $\left({ }^{1} \mathrm{H}\right.$ and ${ }^{13} \mathrm{C}$ NMR spectra for all compounds), and theoretical data (details of computational methods, 45 cartesian coordinates and Gibbs free energies). See DOI: $10.1039 / \mathrm{b} 000000 \mathrm{x} /$
1 For excellent reviews, see: $(a)$ H. W. Gschwend and H. R. Rodriguez, Org. React., 1979, 26, 1-360; (b) V. Snieckus, Chem. Rev., 1990, 90, 879-933.

502 (a) Y. Kondo, M. Shilai, M. Uchiyama and T. Sakamoto, J. Am. Chem. Soc., 1999, 121, 3539-3540; (b) M. Uchiyama, T. Miyoshi, Y. Kajihara, T. Sakamoto, Y. Otani, T. Ohwada and Y. Kondo, J. Am. Chem. Soc., 2002, 124, 8514-8515; (c) H. R. L. Barley, W. Clegg, S. H. Dale, E. Hevia, G. W. Honeyman, A. R. Kennedy and R. E. Mulvey, Angew. Chem. 2005, 117, 6172-6175 (Angew. Chem. Int. Ed., 2005, 44, 6018-6021); (d) W. Clegg, S. H. Dale, E. Hevia, G. W. Honeyman and R. E. Mulvey, Angew. Chem., 2006, 118, 24302434 (Angew. Chem. Int. Ed., 2006, 45, 2370-2374); (e) W. Clegg, S. H. Dale, R. W. Harrington, E. Hevia, G. W. Honeyman and R. E. 60 Mulvey, Angew. Chem., 2006, 118, 2434-2437 (Angew. Chem. Int. Ed., 2006, 45, 2374-2377); (f) W. Clegg, S. H. Dale, A. M. Drummond, E. Hevia, G. W. Honeyman and R. E. Mulvey, J. Am. Chem. Soc., 2006, 128, 7434-7435; (g) M. Uchiyama, Y. Matsumoto, D. Nobuto, T. Furuyama, K. Yamaguchi and K. Morokuma, J. Am. Chem. Soc., 2006, 128, 8748-8750; (h) M. Uchiyama, Y. Kobayashi, T. Furuyama, S. Nakamura, Y. Kajihara, T. Miyoshi, T. Sakamoto, Y. Kondo and K. Morokuma, J. Am. Chem. Soc., 2008, 130, 472-480.

3 (a) M. Uchiyama, H. Naka, Y. Matsumoto and T. Ohwada, J. Am. 70 Chem. Soc., 2004, 126, 10526-10527; (b) J. Garcia-Alvarez, D. V. Graham, A. R. Kennedy, R. E. Mulvey and S. Weatherstone, Chem. Commun., 2006, 30, 3208-3210; (c) J. Garcia-Alvarez, E. Hevia, A. R. Kennedy, J. Klett and R. E. Mulvey, Chem. Commun., 2007, 23, 2402-2404; (d) H. Naka, M. Uchiyama, Y. Matsumoto, A. E. H. Wheatley, M. McPartlin, J. V. Morey and Y. Kondo, J. Am. Chem. Soc., 2007, 129, 1921-1930.

4 J. Garcia-Álvarez, A. R. Kennedy, J. Klett and R. E. Mulvey, Angew. Chem., 2007, 119, 1123-1126 (Angew. Chem. Int. Ed., 2007, 46, 1105-1108).

805 S. Usui, Y. Hashimoto, J. V. Morey, A. E. H. Wheatley and M. Uchiyama, J. Am. Chem. Soc., 2007, 129, 15102-15103.

6 S. H. Wunderlich and P. Knochel, Angew. Chem., 2007, 119, 78297832 (Angew. Chem. Int. Ed. 2007, 46, 7685-7688).

7 For reviews, see: (a) R. E. Mulvey, Organometallics, 2006, 25, 85 1060-1075; (b) R. E. Mulvey, F. Mongin, M. Uchiyama and Y. Kondo, Angew. Chem., 2007, 119, 3876-3899 (Angew. Chem. Int. Ed., 2007, 46, 3802-3824).

8 (a) P. R. Jones and P. J. Desio, Chem. Rev., 1978, 78, 491-516; (b) P. O'Brien and M. A. Malik, Science of Synthesis, 2004, 3, 91-131.

909 G. Wittig, F. J. Meyer and G. Lange, Liebigs Ann. Chem., 1951, 571, 167-201.

10 J.-M. L'Helgoual'ch, A. Seggio, F. Chevallier, M. Yonehara, E. Jeanneau, M. Uchiyama and F. Mongin, J. Org. Chem., 2008, 73, 177-183.

9511 G. Kedarnath, L. B. Kumbhare, V. K. Jain, P. P. Phadnis and M. Nethaji, Dalton Trans., 2006, 2714-2718.

12 A. Seggio, F. Chevallier, M. Vaultier and F. Mongin, J. Org. Chem., 2007, 72, 6602-6605.

13 (a) W. Clegg, S. H. Dale, E. Hevia, L. M. Hogg, G. W. Honeyman,

100 R. E. Mulvey and C. T. O'Hara, Angew. Chem., 2006, 118, 66986700 (Angew. Chem. Int. Ed., 2006, 45, 6548-6550); (b) D. R. Armstrong, W. Clegg, S. H. Dale, D. V. Graham, E. Hevia, L. M. Hogg, G. W. Honeyman, A. R. Kennedy and R. E. Mulvey, Chem. Commun., 2007, 598-600.

10514 L. M. Carrella, W. Clegg, D. V. Graham, L. M. Hogg, A. L. Kennedy, J. Klett, R. E. Mulvey, E. Rentschler and L. Russo, Angew. Chem., 2007, 119, 4746-4750 (Angew. Chem. Int. Ed., 2007, 46, 4662-4666).

15 N. Plé, A. Turck, K. Couture and G. Quéguiner, J. Org. Chem., 1995, $110 \quad$ 60, 3781-3786.

16 To our knowledge, cross-coupling reactions using cadmium compounds have only been described starting from organocadmium chlorides: (a) E.-i. Negishi, T. Takahashi, S. Baba, D. E. Van Horn and N. Okukado, J. Am. Chem. Soc., 1987, 109, 2393-2401; (b) N. Bumagin, A. B. Ponomarev and I. P. Beletskaya, Zh. Org. Khim., 1987, 23, 1345-1353. See also: (c) J. A. Miller and R. P. Farrell, Tetrahedron Lett., 1998, 39, 7275-7278. 
Graphical and textual abstract for the contents pages.

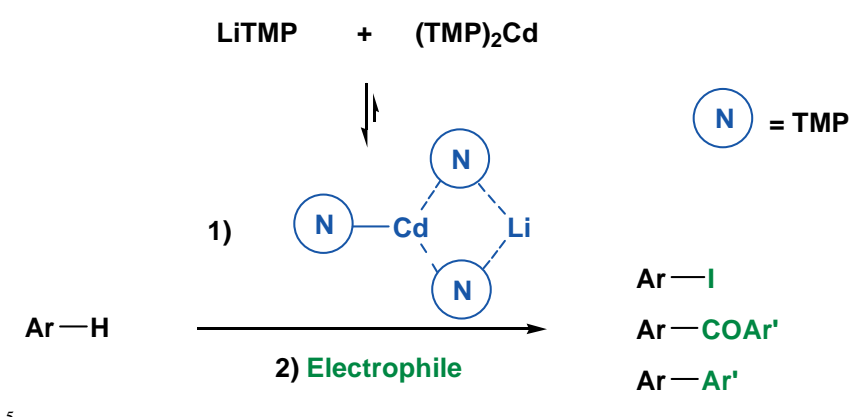

The deproto-metalation of a large range of aromatics including heterocycles is described using a newly developed lithiumcadmium base. The reaction proceeds at room temperature with excellent chemoselectivity and efficiency, and proved to be 10 regioselective in most cases. 